This item was submitted to Loughborough's Research Repository by the author.

Items in Figshare are protected by copyright, with all rights reserved, unless otherwise indicated.

\title{
Fragmentation, auto-modification and post ionisation proton bound dimer ion formation: the differential mobility spectrometry of low molecular weight alcohols
}

\section{PLEASE CITE THE PUBLISHED VERSION}

http://dx.doi.org/10.1039/C6AN00435K

\section{PUBLISHER}

(C) Royal Society of Chemistry

\section{VERSION}

AM (Accepted Manuscript)

\section{PUBLISHER STATEMENT}

This work is made available according to the conditions of the Creative Commons Attribution-NonCommercialNoDerivatives 4.0 International (CC BY-NC-ND 4.0) licence. Full details of this licence are available at: https://creativecommons.org/licenses/by-nc-nd/4.0/

\section{LICENCE}

CC BY-NC-ND 4.0

\section{REPOSITORY RECORD}

Ruszkiewicz, Dorota, Paul Thomas, and Gary Eiceman. 2016. "Fragmentation, Auto-modification and Post Ionisation Proton Bound Dimer lon Formation: The Differential Mobility Spectrometry of Low Molecular Weight Alcohols". Loughborough University. https://hdl.handle.net/2134/21600. 


\section{Analyst}

\section{Accepted Manuscript}

This article can be cited before page numbers have been issued, to do this please use: D. Ruszkiewicz, C. L. P. Thomas and G. A. Eiceman, Analyst, 2016, DOI: 10.1039/C6AN00435K.
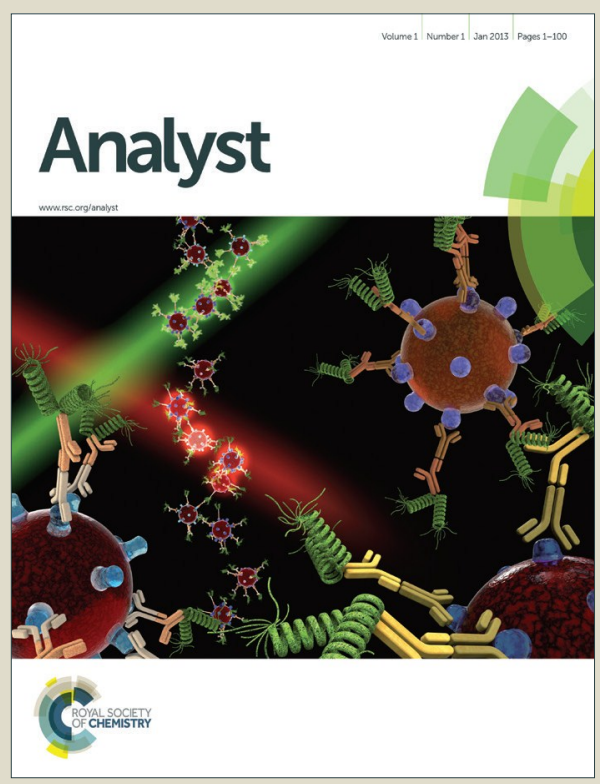

This is an Accepted Manuscript, which has been through the Royal Society of Chemistry peer review process and has been accepted for publication.

Accepted Manuscripts are published online shortly after acceptance, before technical editing, formatting and proof reading. Using this free service, authors can make their results available to the community, in citable form, before we publish the edited article. We will replace this Accepted Manuscript with the edited and formatted Advance Article as soon as it is available.

You can find more information about Accepted Manuscripts in the Information for Authors.

Please note that technical editing may introduce minor changes to the text and/or graphics, which may alter content. The journal's standard Terms \& Conditions and the Ethical guidelines still apply. In no event shall the Royal Society of Chemistry be held responsible for any errors or omissions in this Accepted Manuscript or any consequences arising from the use of any information it contains. 
FRAGMENTATION, AUTO-MODIFICATION AND POST IONISATION PROTON BOUND DIMER ION FORMATION: THE DIFFERENTIAL MOBILITY SPECTROMETRY OF LOW MOLECULAR WEIGHT ALCOHOLS

by Ruszkiewicz D.M., Thomas C.L.P. and Eiceman G.A.

Graphical Abstract
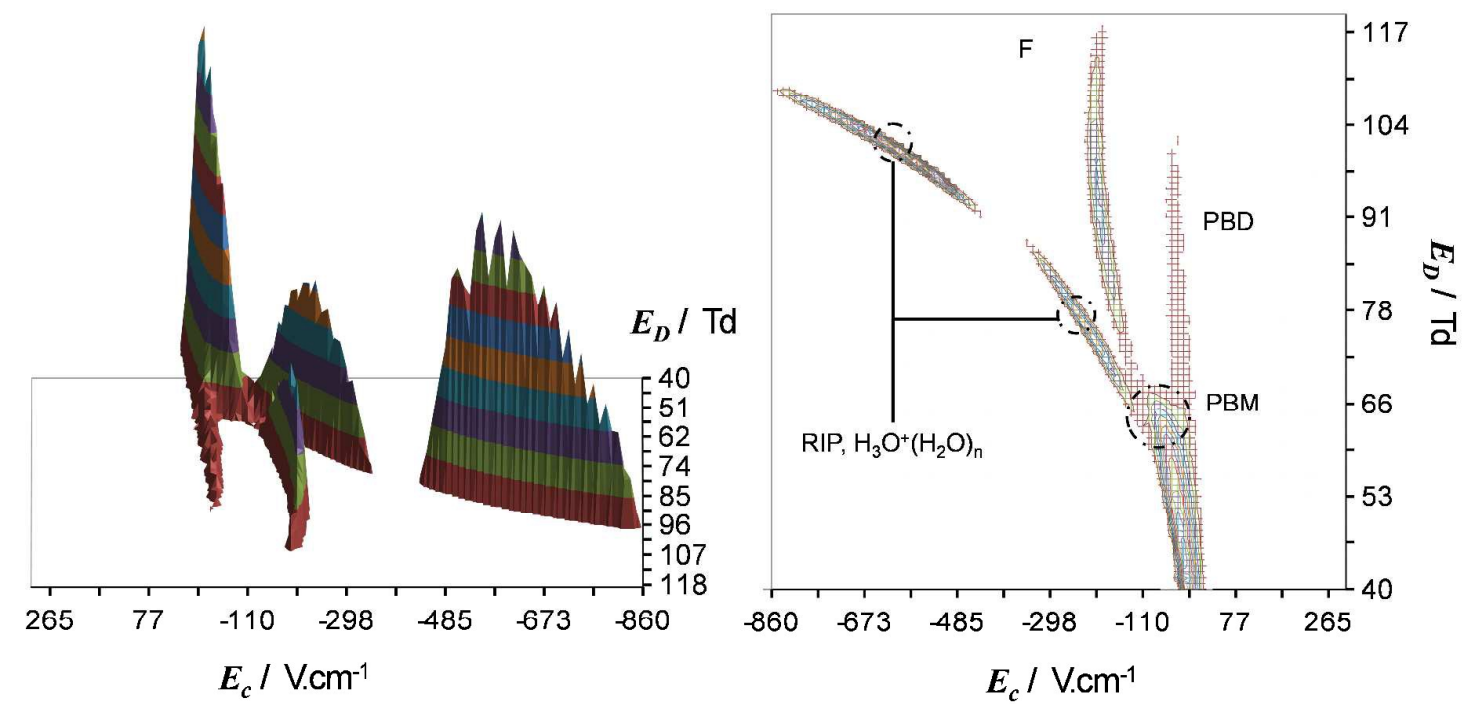

Protonated gas-phase alcohols undergo auto-modification, post-ionisation clustering accompanied by dissociation, fragmentation and dehydration reactions yielding complicated responses in differential mobility spectrometry. Once characterised such behaviours enable enhanced selectivity and confidence in alcohol measurement by differential mobility spectrometry. 
D.M. Ruszkiewicz, C.L.P. Thomas*, G.A. Eiceman

Centre for Analytical Science, Department of Chemistry

Loughborough University

UK

Wednesday, 18 May 2016

\begin{abstract}
The toxicology and societal impacts associated with low molecular weight alcohols frame the requirement for fast diagnostic screens in a wide variety of circumstances. Differential mobility spectrometry (DMS) is currently being used for environmental monitoring of space craft atmospheres and has been proposed for the rapid assessment of patients at accident and emergency receptions.
\end{abstract}

Three studies investigated hitherto undescribed complexity in the DMS spectra of methanol, ethanol, propan-1-ol and butan-1-ol product ions formed from a ${ }^{63} \mathrm{Ni}$ ionisation source. 54,000 DMS spectra obtained over a concentration range of $0.01 \mathrm{mg} \cdot \mathrm{m}^{-3}(\mathrm{~g})$ to $1.80 \mathrm{~g} \cdot \mathrm{m}^{-3}(\mathrm{~g})$ revealed the phenomenon of auto-modification of the product ions. This occurred when the neutral vapour concentration exceeded the level required to induce a neutral-ion collision during the low field portion of the dispersion field waveform. Further, post-ionisation clusterion formation or protonated monomer/proton bound dimer inter-conversion within the ionfilter was indicated by apparent shifts in the values of the protonated monomer compensation field maximum; indicative of post-ionisation conversion of the protonated monomer to a proton-bound dimer.

APCI-DMS-quadrupole mass spectrometry studies enabled the ion dissociation products from dispersion-field heating to be monitored and product ion fragmentation relationships to be proposed. Methanol was not observed to dissociate, while propan-1-ol and butan-1-ol underwent dissociation reactions consistent with dehydration processes that led ultimately to the generation of what is tentatively assigned as a cyclo- $\mathrm{C}_{3} \mathrm{H}_{3}{ }^{+}$ion $(\mathrm{m} / \mathrm{z} 39)$ and hydrated protons.

Studies of the interaction of ion filter temperature with dispersion-field heating of product ions isolated dissociation/fragmentation product ions that have not been previously described in DMS. The implications of these combined findings with regard to data sharing and data interpretation were highlighted. 


\section{INTRODUCTION}

Alcohols' toxicity is a significant problem. Yearly deaths related to alcohols are reported as 15,500 in the UK and 88,000 in the USA [1] with $~ 2.5 \%$ due to acute poisoning [ 2]. The

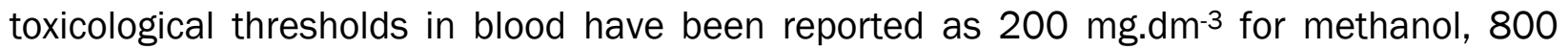
$\mathrm{mg} . \mathrm{dm}^{-3}$ for ethanol, and $400 \mathrm{mg} \cdot \mathrm{dm}^{-3}$ for isopropanol. High toxicity, with a risk-of-death, occurs at blood concentrations of approximately $890 \mathrm{mg} \cdot \mathrm{dm}^{-3}$ for methanol, 3,500 mg. $\mathrm{dm}^{-3}$ for ethanol and 1,500 mg. $\mathrm{dm}^{-3}$ for isopropanol [3].

Methanol is associated with episodic poisoning outbreaks occurring worldwide $[4,5,6]$ from poorly purified or adulterated ethanol based products. It is the subsequent metabolism to formic acid which is responsible for most of methanol's toxic effects in humans, including acidosis, blindness, damage to the central nervous system and death $[4,7]$.

The estimated cost in the United Kingdom for the National Health Service from ethanol misuse is $£ 3.5 .10^{9} \mathrm{yr}^{-1}$ [8]. Such a figure does not account for the wider societal effects associated with ethanol-dependency $[9,10,11]$.

Accidental ingestion of isopropanol has been reported for children [12] and deliberate ingestion by adults, and young-adults in their teenage years, produces intoxication similar to ethanol $[13,14]$. The toxicity of isopropanol is lower than methanol, similar to that of propan-1-ol and higher than that of the ethanol (due to the higher toxicity of the metabolic product acetone) [15]. Some concern has been expressed for the welfare of personnel in closed living quarters, such as spacecraft or submarines, from prolonged and continuous exposure to low concentrations.

Fuel-cell based sensors are commonly associated with the determination of the level of ethanol in breath for law enforcement. Other approaches have been described for the analysis of alcohols in air, breath, and include: gas chromatography (GC) $[16,17,18]$; mass spectrometry (MS) [19, 20, 21]; ion mobility spectrometry [22]; and, differential ion mobility spectrometry (DMS) [23]. Of particular interest to this study is the determination of alcohols by the Air Quality Monitor, a hyphenated and thoroughly integrated GC-DMS instrument, used on-board the International Space Station [24].

The formation of product ions within a DMS has been described elsewhere [25]. At ambient temperatures alcohols $(\mathrm{R}-\mathrm{OH})$ react through atmospheric pressure chemical ionisation (APCI) 
reactions with a hydrated proton reactant ions $\left(\mathrm{H}^{+}\left(\mathrm{H}_{2} \mathrm{O}\right)_{n}\right)$ to form protonated monomers clustered with water through a displacement reaction, (1):

$\mathrm{R}-\mathrm{OH}+\mathrm{H}^{+}\left(\mathrm{H}_{2} \mathrm{O}\right)_{n} \longrightarrow\left\{(\mathrm{R}-\mathrm{OH}) \mathrm{H}^{+}\left(\mathrm{H}_{2} \mathrm{O}\right)_{n-1}\right\}+\mathrm{H}_{2} \mathrm{O}$

As concentrations of the alcohol (R-OH) increase, additional ion clusters, such as a protonbound dimer, are formed per (2):

$\mathrm{R}-\mathrm{OH}+\left\{(\mathrm{R}-\mathrm{OH}) \mathrm{H}^{+}\left(\mathrm{H}_{2} \mathrm{O}\right)_{\mathrm{n}-1}\right\} \longrightarrow\left\{(\mathrm{R}-\mathrm{OH})_{2} \mathrm{H}^{+}\left(\mathrm{H}_{2} \mathrm{O}\right)_{\mathrm{n}-2}\right\}+\mathrm{H}_{2} \mathrm{O}$

Increasing the alcohol concentration to ever higher levels can promote the formation of alcohol clusters $(\mathrm{R}-\mathrm{OH})_{n}$ including proton bound trimers $(n=3)$, tetramers $(n=4)$, and higher, reaching $n=8$ in highly enriched atmospheres. Note though that $n$ depends on temperature [25].

As ion energy, expressed as effective ion temperature $\left(T_{e f f}\right)$, is increased alcohol product ions decompose, and findings from proton transfer reaction mass spectrometry [26,27] describe the dehydration of protonated monomers with increasing electric field $(E / N)$ strength; $T_{\text {eff }}$ was increased, see (3) and (4).
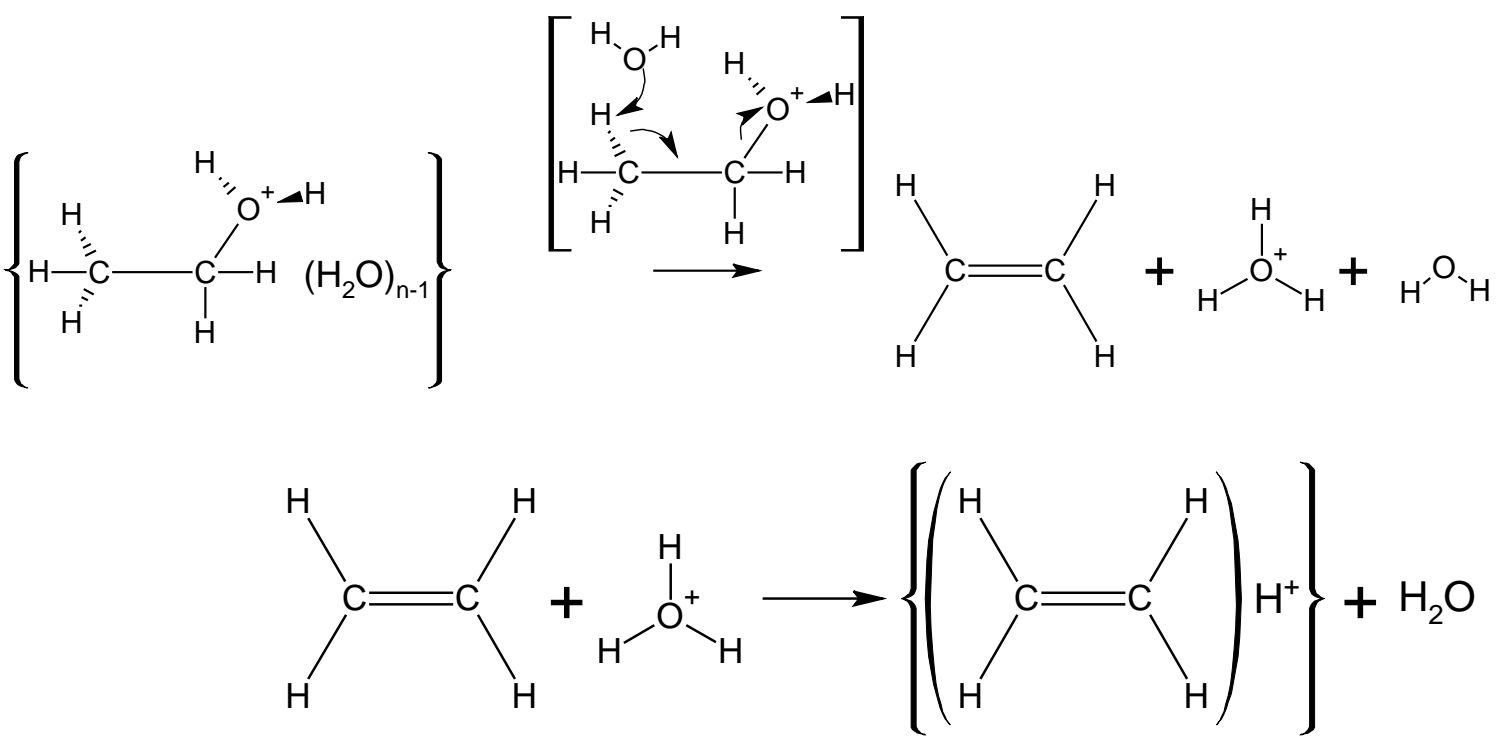
As energies are increased $\left(T_{e f f}\right)$, the protonated alkene can fragment further, (4). These reactions have been observed at sub-ambient pressures with electric-fields of $100 \mathrm{~T}_{\mathrm{d}}$; not unlike the field-strengths encountered with DMS.

$$
\begin{aligned}
& \left\{\mathrm{C}_{5} \mathrm{H}_{11} \mathrm{O}^{+} \mathrm{H}_{2}\left(\mathrm{H}_{2} \mathrm{O}\right)_{\mathrm{n}-1}\right\} \\
& \quad\left\{\mathrm{C}_{5} \mathrm{H}_{11}^{+}\left(\mathrm{H}_{2} \mathrm{O}\right)_{\mathrm{n}-1}\right\} \stackrel{-\mathrm{H}_{2} \mathrm{O}}{\longrightarrow}\left\{\mathrm{C}_{5} \mathrm{H}_{11}{ }^{+}\left(\mathrm{H}_{2} \mathrm{O}\right)_{\mathrm{n}-1}\right\} \\
& \underset{\Delta T_{E f f}}{\longrightarrow} \mathrm{C}_{2} \mathrm{H}_{4}+\left\{\mathrm{C}_{3} \mathrm{H}_{7}^{+}\left(\mathrm{H}_{2} \mathrm{O}\right)_{\mathrm{n}-1}\right\} \underset{\Delta T_{E f f}}{\longrightarrow} \mathrm{C}_{2} \mathrm{H}_{4}+\left\{\mathrm{C}_{3} \mathrm{H}_{7}^{+}\left(\mathrm{H}_{2} \mathrm{O}\right)_{\mathrm{n}-1}\right\}
\end{aligned}
$$

In DMS, ions are passed by a transport gas through a channel formed from two parallel plates, the ion filter. A transverse alternating asymmetric electric field is applied across the filter and the resultant ion oscillations cause a net displacement in the ion's trajectory from the central-axis of the ion filter. This happens when ion mobility coefficients are field dependent, $K_{(E / N)}$, as shown in Equation 1 [25]:

$K_{(E / N)}=K_{(0)}\left(1+\alpha_{(E / N)}\right)$

Eqn. 1

Here $\alpha_{(E / N)}$ is a function with a polynomial fit of even powers which describes the change of the ion mobility coefficient $(K)$ with electric field strength $(E)$ normalized to the number density $(N)$ as shown in Equation 2:

$\alpha_{(E / N)}=\alpha 1_{(E / N)}^{2}+\alpha 2_{(E / N)}^{4}+\alpha 3_{(E / N)}^{6}+\ldots$

Eqn. 2

When the mobility coefficient $\left(K_{(E / N)}\right)$ increases disproportionately with increased $E / N$ or increased dispersion field $\left(E_{d}\right)$, the alpha-function is termed positive and this behaviour may be attributed to several processes, the most significant of which is a cluster-decluster mechanism induced by the alternating asymmetric dispersion-field. A negative alphafunction may also be observed when the mobility coefficient decreases disproportionately with increasing dispersion-field as a result of ion heating through increased collision frequency and drag forces. The displaced ion trajectories may be restored to a stable path 
at the centre of the ion-filter and passed to a detector by applying a continuous weak dc electric field; termed the compensation-field.

Alpha-functions can be changed by modifying the transport gas with low molecular weight polar molecules (modifiers) at concentrations between $0.1 \%(\mathrm{v} / \mathrm{v})$ to $3 \%(\mathrm{v} / \mathrm{v})$. Modification of the transport gas with alcohols and other small polar molecules, including water, significantly changes the cluster-decluster phenomenon for positive alpha-function species and results in a displacement of the ion peak on the compensation-field scale. Such changes in compensation field can lead to improved separation of ion peaks [25, 28].

The DMS spectral responses observed from the wide range of alcohol concentrations that may be encountered in direct breath monitoring for toxicity may be subject to combination of "auto-modification" of the transport gas by the alcohol analytes and post-ionisation dissociation of the protonated molecular ions. In parallel to this interest is the influence of GC-DMS instrument parameters on the resultant signals observed from samples taken onboard spacecraft. Consequently, the objective of the current study was to elucidate DMS responses to alcohols over a range of instrument parameters, with a particular interest in the influence of the dispersion-field $(E / N)$ and transport gas temperature at ambient pressure.

\section{EXPERIMENTAL}

\section{Instrumentation}

A differential mobility spectrometer (model SVAC-V, Sionex; MA, USA) with a $5.0 \mathrm{MBq}$ foil of ${ }^{63} \mathrm{Ni}$ ionisation source was operated with $1.18 \mathrm{MHz}$ asymmetric waveform over a dispersion field $\left(E_{C}\right)$ range $40 \mathrm{Td}$ to $120 \mathrm{Td}$; the instrument setting was $10 \mathrm{kV} . \mathrm{cm}^{-1}$ to 30 $\mathrm{kV} . \mathrm{cm}^{-1}$. The compensation field could be scanned from -3 Td to $1 \mathrm{Td}$; $-860 \mathrm{~V} . \mathrm{cm}^{-1}$ to +300 V.cm-1. The electrode-gap in the ion filter was $0.5 \mathrm{~mm}$ and the analyser region was $20 \mathrm{~mm}$ long. The instrument was operated using Sionex Expert software, Version 2.01. The transport-gas $\left(300 \mathrm{~cm}^{3} \cdot \mathrm{min}^{-1}\right.$ to $320 \mathrm{~cm}^{3} \cdot \mathrm{min}^{-1}$ ) was purified nitrogen and water concentration was routinely monitored with a moisture monitor (Series 35 from Panametrics, UK) and maintained at $25 \mathrm{mg} \cdot \mathrm{m}_{(\mathrm{g})}^{-3} \pm 5 \mathrm{mg} \cdot \mathrm{m}_{(\mathrm{g})}^{-3}(34 \mathrm{ppm}(\mathrm{v} / \mathrm{v}) \pm 8 \mathrm{ppm}$ $(\mathrm{v} / \mathrm{v}))$. The transport gas was mixed with the eluent from a heated $500 \mathrm{~cm}^{3}$ round bottom 
exponential flask $\left(7 \mathrm{~cm}^{3} \cdot \mathrm{min}^{-1}\right.$ to $\left.19 \mathrm{~cm}^{3} \cdot \mathrm{min}^{-1}\right)$, or a permeation source based test atmosphere generator.

A Shimadzu model 2020 mass spectrometer (Columbia, MD) was interfaced to a DMS constructed in-house using materials, dimensions, electronic control, and an ion source similar to the SVAC-V. The inlet for the DMS/MS instrument was comparable to the SVAC-V DMS. Note that in this experiment the dispersion field was used to induce ion heating and not separate the ions, and had a sinusoidal waveform. The DMS assembly included two ceramic plates with thickness of $1 \mathrm{~mm}$, length of $30 \mathrm{~mm}$, and width of $25 \mathrm{~mm}$ separated by a Teflon gasket $(0.5 \mathrm{~mm} \times 30 \mathrm{~mm} \times 25 \mathrm{~mm})$ with a $3 \mathrm{~mm}$ wide centre channel for gas and ion flow. These were held between two Teflon plates (4 mm x $30 \mathrm{~mm} \times 25 \mathrm{~mm}$ ) and secured under compression by two aluminium plates ( $5 \mathrm{~mm} \times 30 \mathrm{~mm} \times 25 \mathrm{~mm}$ ) with six screws. At each end of this assembly were aluminium end caps $(20.5 .5 \mathrm{~mm} \times 5 \mathrm{~mm}$ x $25 \mathrm{~mm}$ ) attached to the aluminium plates with four screws. An 1/8" stainless steel union (Swagelok Corp., El Paso Valve and Fitting, El Paso, TX) was threaded into one cap, for inlet flow. A $111 \mathrm{MBq}{ }^{63} \mathrm{Ni}$ foil was fitted into the interior volume of this fitting. In the other cap, for connection to the mass spectrometer, a stainless 1/8" to 1/16" reducing union (Swagelok) was threaded and the capillary line from the mass spectrometer was held by compression in the 1/16" end of the union. This assembly was insulated using glass fibre insulating sheeting and the temperature was controlled by conduction from the transfer line, heated using resistive wire.

\section{Chemicals and Reagents}

Methanol, ethanol, propan-1-ol, and butan-1-ol were obtained from Fisher Chemicals, Loughborough, UK; GC and HPLC purity $\geq 99.5 \%$. The alcohols were purified further by purging with high-purity nitrogen and then analysed by GC-MS, The results of which indicated a purity $\geq 99.9 \%$ with an additional peak identified as chloroform, which was used for cleaning the syringe, at an abundance of $<0.02 \%$ of the respective alcohol peaks. Figure S1 shows an example GC-MS of the purity analysis, and the properties of each alcohol are given in Supplemental Table S1. 
Methods

Effect of Vapour Concentration.

Alcohol test-atmospheres were delivered to the DMS at fixed dispersion-fields over six orders of magnitude concentration range by injecting $75 \mu \mathrm{l}$ to $200 \mu \mathrm{l}$ of a pure alcohol standard into a heated inlet, with a flow of between $6 \mathrm{~cm}^{3} \cdot \mathrm{min}^{-1}$ to $19 \mathrm{~cm}^{3} \cdot \mathrm{min}^{-1}$ of purified air passing into the exponential dilution flask [29, 30, 31]. The exhaust from the exponential dilution flask was subsequently mixed into the transport gas of the DMS analyser; see above. A schematic of the experimental arrangement is shown in Supplemental Figure S2. Differential mobility spectra were continuously recorded by scanning the compensation field (ca. $1 \mathrm{~Hz}$, see above) for between $12 \mathrm{hr}$ to $15 \mathrm{hr}$, generating up to 54,000 spectra per experiment. The experimental conditions were selected to inhibit ion fragmentation while operating at the highest ion-filter temperature $(T)$ possible (to reduce adsorption and hysteresis effects) and the lowest dispersion field $\left(E_{D}\right)$ required to ensure resolution between the reactant and product ion species. The values chosen were: methanol $T=60^{\circ} \mathrm{C}$ and $E_{D}=117.6 \mathrm{Td}\left(29.4 \mathrm{kV} . \mathrm{cm}^{-1}\right)$; ethanol, $T=35^{\circ} \mathrm{C}$ and $E_{D}=72 \mathrm{Td}\left(18 \mathrm{kV} . \mathrm{cm}^{-1}\right)$ and, for propan-1-ol $T=60^{\circ} \mathrm{C}$ and $E_{D}=88 \mathrm{Td}\left(22 \mathrm{kV} . \mathrm{cm}^{-1}\right)$. Other parameters for the operation of the DMS analyser are given in Supplemental Table S2. The effective temperature of an ion $\left(T_{e f f}\right)$ was calculated for each dispersion-field investigated in the study by applying $1.5^{\circ} \mathrm{C}$ $\mathrm{Td}^{-1}$ to the ion-filter temperature [32].

\section{Mass Analysis of lons}

The identity of fragment ions produced by dispersion field heating was studied by a DMS/MS connected to dynamic test atmosphere generator where test-atmospheres were delivered to the DMS/MS from a $3 \mathrm{dm}^{3}$ exponential dilution flask at a flow rate of $1 \mathrm{dm}^{3} \cdot \mathrm{min}^{-1}$ following the injection and mixing of $0.4 \mu \mathrm{l}$ of a pure alcohol standard into the exponential dilution flask. The mass spectrometer was scanned continuously from m/z 20 to m/z 400 at $0.5 \mathrm{~Hz}$ over the analytes' concentration ranges of $0.02 \mathrm{mg} \cdot \mathrm{m}^{-3}(\mathrm{~g})$ to $100 \mathrm{mg} \mathrm{m}^{-3}(\mathrm{~g})$.

\section{Studies of Effective Temperature of Ions $\left(\boldsymbol{T}_{\text {eff }}\right)$}

Studies of the influence of ion temperature, $\left(T_{e f f}\right)$ at a constant analyte concentration used permeation sources to generate test atmospheres. Pure alcohol standards were dispensed 
into $2.9 \mathrm{~cm}^{3}$ chromatography vials and sealed with either a $0.5 \mathrm{~mm}$ or $0.1 \mathrm{~mm}$ thick PTFE membrane. The permeation sources were maintained at $40^{\circ} \mathrm{C}$ for a period of five weeks and calibrated gravimetrically. A test atmosphere generator (TAG), using filtered compressed air as a diluent gas, was constructed to mix constant concentration test atmospheres into the DMS transport-gas, and replaced the exponential dilution flask in the inlet to the experiment. A schematic of the experimental arrangement is shown in Supplemental Figure S2. The concentrations of the analytes ranged from $25 \mu \mathrm{g} \cdot \mathrm{m}^{-3}(\mathrm{~g})$ to $1 \mu \mathrm{g} \cdot \mathrm{m}^{-3}(\mathrm{~g})$. Data were recorded in the form of dispersion plots with compensation-field scans (see above) run against a programmed increase in the dispersion field-strength; across the range 40 Td to $120 \mathrm{Td}$ (10 $\mathrm{kV} . \mathrm{cm}^{-1}$ to $30 \mathrm{kV} . \mathrm{cm}^{-1}$ ), at ion-filter temperatures across the range $45^{\circ} \mathrm{C}$ to $130^{\circ} \mathrm{C}$.

Further details of data acquisition, experimental parameters, and the permeation sources are given in the Supplemental Tables S2 and S3.

\section{RESULTS AND DISCUSSION}

\section{Concentration Dependence of Differential Mobility Spectra of Alcohols}

The objective of this experiment was to reveal auto-modification phenomena, and possible ion clustering artefacts in the DMS ion filter, see below. To do this the potential formation of ion fragments that would obscure the experimental observations needed to be prevented. This required balancing three experimental parameters: the ion temperature $T_{\text {eff }}$ was to be kept below the threshold at which fragment ions would be generated; the ion-filter temperature was to be set at a temperature high enough to limit adsorption and hysteresis within the instruments that would confound the measurements; and, the dispersion field was selected at the lowest value required to provide resolution between the reactant and product ions without causing enough ion heating to induce ion fragmentation. Differential mobility spectra for methanol, ethanol, and propan-1-ol at gas temperatures of $30^{\circ} \mathrm{C}$ and $60^{\circ} \mathrm{C}$ are shown in Figure 1 as contour plots of ion intensity, compensation field strength $\left(E_{C} / \mathrm{V} \cdot \mathrm{cm}^{-1}\right.$ and $\left.\mathrm{Td}\right)$, and $\mathrm{In}$ (concentration) from $0.01 \mathrm{mg} \cdot \mathrm{m}^{-3}(\mathrm{~g})$ to $1.80 \mathrm{~g}^{-3} \mathrm{~m}^{-3}(\mathrm{~g})$. At low concentrations ion peaks for protonated monomer, proton-bound dimer and residual levels for the hydrated proton reactant ion peak (RIP) were discerned. The responses for all three 
compounds followed similar trends; exemplified by the ethanol responses; middle trace Figure 1.

At concentrations below $0.2 \mathrm{mg} \cdot \mathrm{m}^{-3}(\mathrm{~g})$ and at a temperature of $35^{\circ} \mathrm{C}$ the ethanol responses show a residual RIP, a protonated monomer and a proton bound dimer at compensation fields $\left(E_{c}\right)$ of $-0.72 \mathrm{Td}\left(-180 \mathrm{~V} . \mathrm{cm}^{-1}\right),-0.63 \mathrm{Td}\left(158 \mathrm{~V} . \mathrm{cm}^{-1}\right)$ and $-0.2 \mathrm{Td}\left(50 \mathrm{~V} . \mathrm{cm}^{-1}\right)$ respectively. The peaks are not fully resolved. As the concentration increases to $0.4 \mathrm{mg} \cdot \mathrm{m}^{-3}$ (g) the RIP and protonated monomer are depleted and the proton bound dimer becomes the dominant ion species, consistent with (1) and (2). Calculations of distributions of ions at these concentrations are generally consistent with relative peak abundances seen in Figure 1 (Supplemental Figure S3 shows an example calculation). These patterns were observed for all alcohols with appropriate $E_{c}$ values for field dependent mobility. Peak widths at half height were ca. $0.5 \mathrm{Td}\left(126 \mathrm{~V} . \mathrm{cm}^{-1}\right)$.

Above concentrations of $0.2 \mathrm{mg} \cdot \mathrm{m}^{-3}(\mathrm{~g})$, the $E_{c}$ values of the protonated and proton bound dimer merged with a continuous shift in $E_{c}$ for the proton bound dimer peak from $-2.0 \mathrm{Td}$ to $+0.32 \mathrm{Td}$ at a concentration of approximately $100 \mathrm{mg} \cdot \mathrm{m}^{-3}(\mathrm{~g})$. Calculations of ion distributions show that at $\left.50 \mathrm{mg} \cdot \mathrm{m}^{-3} \mathrm{~g}\right)$ the fractional value for proton-bound trimer is 0.75 and trends toward a maximum at $200 \mathrm{mg} \cdot \mathrm{m}^{-3}(\mathrm{~g})$ (the fractional value of proton-bound tetramer increases over 0.001 only at $\left.400 \mathrm{mg}^{-3} \mathrm{~m}^{-3} \mathrm{~g}\right)$. Since ions and unreacted sample vapour flow together through the ion filter, the shift in the peaks' compensation-field values over the range $0.01 \mathrm{mg} \cdot \mathrm{mg}^{-3}(\mathrm{~g})$ to $100 \mathrm{mg} \cdot \mathrm{m}^{-3}(\mathrm{~g})$ may be attributed to the sequential formation of the proton bound dimer, from the protonated monomer, and then, as the concentration increases still further, the formation of proton bound trimer; denoted as a proton-bound cluster ion "PBCL" in Figure 1.

At concentrations above $100 \mathrm{mg}^{-3} \mathrm{~m}^{-3}$ the trend in the PBCL peak $E_{c}$ shift reversed, so that at a concentration of $1800 \mathrm{mg} \cdot \mathrm{m}^{-3}$ the PBCL peak had an apparent $E_{c}$ of $-0.7 \mathrm{Td}$. Such modification of the alpha-function by high concentrations of ethanol has been described extensively in the DMS literature, and the phenomenon of an analyte modifying its DMS response may be termed auto-modification.

This interpretation of the observed responses implies that ion lifetimes exceed their residence time in the ion-filter and that ion temperatures are slightly higher than the gas 
temperature since the effective temperature of the ion $\left(T_{e f f}\right)$ is increased by absorbing field energy according to Equation 3:

$$
\frac{3}{2} k_{b} T_{e f f}=\frac{3}{2} k_{b} T+\frac{1}{2} \zeta M v_{d}^{2}
$$

where: $k_{b}$, Boltzmann constant; $T$, gas temperature; $M$, ion mass; and $v_{d}$, drift velocity of the ion swarm given by,

$$
v_{d}^{2}=K_{0}^{2} N_{0}^{2}\left(\frac{E}{N}\right)^{2}
$$

Eqn. 4

The term $\zeta$ is a correction for inefficient transfer of field energy to the ion for fragmentation. A correction from thermal to field supplemented $T_{\text {eff }}$ is $1.5^{\circ} \mathrm{C}$ per $\mathrm{Td}$ has been reported previously in two studies [31,33].

Spectra obtained with the DMS analyser at $100^{\circ} \mathrm{C}$ (Figure 2), a typical temperature for analytical applications with GC/DMS instrumentation, exhibited significant differences from those described in Figure 1. A prominent difference was observed in the case of propan-1ol, with ion peaks for protonated monomer and proton bound dimer being absent over the concentration range $0.02 \mathrm{mg} \cdot \mathrm{m}^{-3}$ (g) to ca. $3 \mathrm{mg} \cdot \mathrm{m}^{-3}$ (g) with a resolved RIP below concentrations of ca. $0.2 \mathrm{mg} \mathrm{m}^{-3}$ (g). Another significant difference was the appearance of additional ion peak at an $E_{c}$ of $-1.10 \mathrm{Td}$, indicative of a smaller ion than the protonated monomer ion over a concentration range from $0.02 \mathrm{mg} \cdot \mathrm{m}^{-3}$ to $3 \mathrm{mg} \cdot \mathrm{m}^{-3}$. Similar behaviour was also observed for ethanol, but not methanol, and these observations are indicative of fragmentation reactions.

Previous studies with proton transfer reaction mass spectrometry described the dehydration of protonated alcohols above electric-field strength of $92 \mathrm{Td}$, followed by dehydrogenation when the electric-field strength was increased above $138 \mathrm{Td}$ [27]. The combined effect of temperature and electric-field was not described. Direct extrapolation of such mass spectrometric findings to DMS with a polarizable atmosphere with increased $\mathrm{N}$ was not considered trivial and consequently, studies of $T$ and dispersion-field (E/N) interactions were undertaken and are described below. 
APCI Mass Spectrometry of Alcohols with Electric Field Induced Decomposition of Ions lons formed in a ${ }^{63} \mathrm{Ni}$ ion source and heated with electric fields were mass-analysed and Figure 3 describes the data obtained from propan-1-ol and butan-1-ol challenges showing how ion abundance changed as the electric-field amplitude was increased.

\section{Propan-1-ol}

At the lowest electric field strengths, below an applied voltage amplitude of $1.7 \mathrm{kV}$ the proton bound dimer m/z 121 was most prominent (375 counts) with two dissociation products at $\mathrm{m} / \mathrm{z} 61$ (75 counts) and $\mathrm{m} / \mathrm{z} 43$ (250 counts) also present. Increasing the voltage amplitude to ca. $2.2 \mathrm{kV}$ resulted in the depletion of the proton bound dimer with the abundance of the $\mathrm{m} / \mathrm{z} 61$ and $\mathrm{m} / \mathrm{z} 43$ reaching maximum intensities of ca 370 counts and 340 counts respectively. Note however that another dissociation product, $\mathrm{m} / \mathrm{z} 59$, was created in parallel with the m/z 61 and m/z 43 entities, increasing in-line with increasing voltage amplitude. Above a voltage of $2.2 \mathrm{kV}$ the $\mathrm{m} / \mathrm{z} 59$ dissociation product ion became the dominant species, reaching a maximum intensity at $2.5 \mathrm{kV}$, as the abundance of $\mathrm{m} / \mathrm{z} 61$ and $\mathrm{m} / \mathrm{z} 43$ ions reduced to near zero. Finally, at an applied voltage above $2.5 \mathrm{kV}$ the abundance of $\mathrm{m} / \mathrm{z} 59$ fragment ion reduced to near zero accompanied by the emergence of $\mathrm{m} / \mathrm{z} 39$ dissociation product ion reaching a maximum intensity estimated to fall in the range 180 counts to 300 counts at an applied voltage of $2.9 \mathrm{kV}$.

\section{Butan-1-ol}

The electric field induced fragmentation of butan-1-ol revealed similar, albeit more complicated, behaviours to those observed for propan-1-ol. Below an applied voltage amplitude of $1.7 \mathrm{kV}$ the proton bound dimer $(\mathrm{m} / \mathrm{z}=149)$ was most prominent. Above this value the proton bound dimer depleted rapidly with an approximate $10 \%$ yield of a dissociation product ion $(\mathrm{m} / \mathrm{z}=57)$ and an approximately $1 \%$ yield of hydrated protonated monomer $(\mathrm{m} / \mathrm{z}=93)$, Figure 3 . Increasing the voltage amplitude to $3 \mathrm{kV}$ resulted in the formation of another dissociation product ion $(\mathrm{m} / \mathrm{z}=39)$. The relationship of the yield of the $\mathrm{m} / \mathrm{z} 93$ product ion (hydrated protonated monomer) to the voltage amplitude was not as well defined as the other species; perhaps indicating the possibility of two overlapping and unresolved profiles. The most abundant dissociation product ion appeared to be related to the formation of $\mathrm{m} / \mathrm{z}=57$ species. However the formation of $a \mathrm{~m} / \mathrm{z}=39$ dissociation 
product ion, at low yields (ca. $0.3 \%$ of the proton bound dimer intensity), starting at a dispersion voltage amplitude of about $2.5 \mathrm{kV}$ indicates a carbon-carbon bond cleavage accompanied by the formation of a smaller single carbon atom entity (possibly protonated formaldehyde) that was not observed in this experiment. The appearance of the $\mathrm{m} / \mathrm{z}=39$ species coincides with the maximum yield of the $\mathrm{m} / \mathrm{z}=93$ and $\mathrm{m} / \mathrm{z}=57$ dissociation product ions.

\section{Influence of Temperature and Dispersion Field}

Dispersion plots for methanol, propan-1-ol, and butan-1-ol obtained at temperatures over the range $40^{\circ} \mathrm{C}$ to $120^{\circ} \mathrm{C}$ at constant concentrations are shown in Figures 4 to 6 .

\section{Methanol}

Methanol (Figure 4) may be regarded as a reference experiment where the effect of increasing the cell-temperature on differential mobility may be discerned. The alpha-function for the protonated methanol monomer was little affected by cell-temperature, with the cluster ion $\mathrm{CH}_{3} \mathrm{OH}_{2}^{+}\left(\mathrm{H}_{2} \mathrm{O}\right)_{n}$ being principally a mono-hydrate. (Fractional values for $n=2$ were calculated to be 0.14 at $80^{\circ} \mathrm{C}, 0.05$ at $100^{\circ} \mathrm{C}$, and 0.01 at $120^{\circ} \mathrm{C}$ ). Nonetheless, changes in the alpha function for these ions were measurable and separation of the reactant ion and product ion peaks occurred at dispersion fields that decreased with increased temperature: $98 \mathrm{Td}\left(24.5 \mathrm{kV} . \mathrm{cm}^{-1}\right)$ at $80^{\circ} \mathrm{C}, 89 \mathrm{Td}\left(22.25 \mathrm{kV} . \mathrm{cm}^{-1}\right)$ at $100^{\circ} \mathrm{C}$ and $78 \mathrm{Td}\left(19.5 \mathrm{kV} . \mathrm{cm}^{-1}\right)$ at $120^{\circ} \mathrm{C}$. Increasing cell-temperature also boosts the $T_{\text {eff }}$ of the product ion while changing the nature of the low-field cluster ion at higher dispersion fields. It is helpful to note that differential mobilities are determined by difference between the low-field, and high-field mobilities that product ions experience throughout the asymmetric waveform of the dispersion field. (Increasing cell temperature results in the mobilities of the low field ion clusters tending towards their high-field forms so reducing their differential mobility).

A minor presence of a feature attributed to an ammonium ion was observed in all methanol dispersion plots. The source of this impurity was not identified and it was not detected in the GC-MS purity assays. Note that no proton-bound methanol dimer or fragment ions were observed throughout this range of cell-temperatures and dispersion field strengths. 


\section{Propan-1-ol}

Dispersion plots in Figure 5 for propan-1-ol from 70 to $130^{\circ} \mathrm{C}$ indicated complicated behaviours, with a feature possibly attributable to a protonated monomer discernible only at $70^{\circ} \mathrm{C}$ and then only at $E_{D}$ values between $60 \mathrm{Td}\left(15 \mathrm{kV} . \mathrm{cm}^{-1}\right)$ to $75 \mathrm{Td}\left(18.75 \mathrm{kV} . \mathrm{cm}^{-1}\right)$. A cluster ion was observed at $E_{D}$ values from $40 \mathrm{Td}\left(10 \mathrm{kV} \cdot \mathrm{cm}^{-1}\right)$ to $100 \mathrm{Td}(25 \mathrm{kV} . \mathrm{cm}-1)$. This feature depleted rapidly with increasing $E_{D}$ value and as the ion-filter temperature was increased the $E_{D}$ value at which this feature ended appeared to reduce significantly. An unexpected and previously unreported phenomenon was the apparent regeneration of the RIP signal that accompanied disappearance of the cluster ion signal, indicating the creation of hydrated protons. Figure 6, taken from propan-1-ol dispersion data at a cell-temperature of $70^{\circ} \mathrm{C}$ shows the extracted $\left(\left(\mathrm{H}_{3} \mathrm{O}\right)^{+}\left(\mathrm{H}_{2} \mathrm{O}\right)_{\mathrm{n}}\right)$ maximum dispersion plot signal. As $E_{D}$ increased the intensity of the $\left(\left(\mathrm{H}_{3} \mathrm{O}\right)^{+}\left(\mathrm{H}_{2} \mathrm{O}\right)_{n}\right)$ signal increased from an almost zero level starting at $65 \mathrm{Td}\left(17.25 \mathrm{kV} . \mathrm{cm}^{-1}\right)$ and reaching a maximum at $84 \mathrm{Td}\left(21 \mathrm{kV} . \mathrm{cm}^{-1}\right)$, followed by a decline. In contrast the blank dispersion plot shows peak intensity decreasing smoothly with increasing $E_{D}$ due to wall-losses associated with the reduction in the acceptance aperture that occurs with increasing $E_{D}$; observed for all ions in planar embodiments of DMS. Any rise in ion intensity with increasing $E_{D}$, as shown for propan-1-ol, originates from a chemical reaction and suggests formation of $\left(\mathrm{H}^{+}\left(\mathrm{H}_{2} \mathrm{O}\right)_{n}\right)$.

Accompanying the depletion of the cluster ion signal was an appearance of another ion $\left(E_{C}\right.$ $=-1.5 \mathrm{Td}\left(-473 \mathrm{~V} . \mathrm{cm}^{-1}\right) ; E_{D}=117 \mathrm{Td}\left(29.25 \mathrm{kV} . \mathrm{cm}^{-1}\right)$. The appearance of this ion at increasingly lower $E_{D}$ values with increased temperature was consistent with the pattern of ion dissociation/fragmentation seen in the DMS-MS experiment used to study electric field induced decomposition, Figure 3.

The instruments used in this study were not able to isolate and characterise fully the ion clusters observed; this will require the design and construction of a new DMS-MS instrument that isolates the product ions from neutral species before the ion filter. The underlying processes that generated the observed responses may be described in similar terms to the chemistry of alcohol product ions observed with PTRMS [27]. At low $E_{D}$ and ion filter temperature the predominant propan-1-ol species appears to be a proton bound dimer (m/z 
121), increasing the energy of the ion cluster causes dissociation generating a product ( $\mathrm{m} / \mathrm{z}$ 61) thought to be a protonated monomer (5)

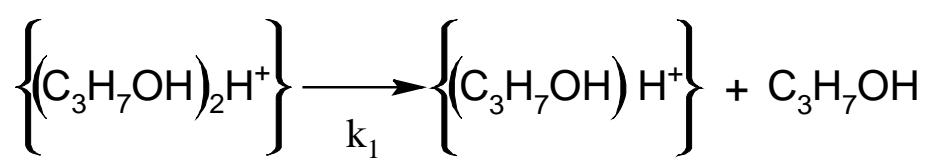

The protonated monomer may undergo a dehydration reaction (6) resulting in a fragment ion (m/z 43), reported previously in PTRMS studies at electric fields of 138 Td [27].

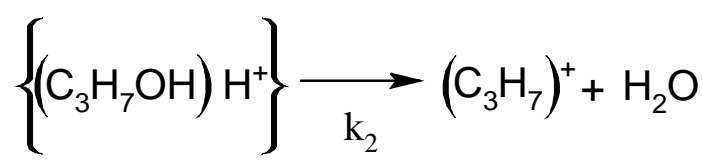

The creation of an m/z 59 entity from propan-1-ol has not been reported, although it was observed at trace levels with propan-2-ol. Proton bound dimers were also not reported within PTRMS studies, and the difference in pressure and chemical speciation indicates that different fragmentation mechanisms may exist. The creation of $\mathrm{m} / \mathrm{z} 59$ species along with the production of $\mathrm{m} / \mathrm{z} 43$ and $\mathrm{m} / \mathrm{z} 19$ may be invoked through the dissociation of a proton bound dimer (7).

$\left\{\left(\mathrm{C}_{3} \mathrm{H}_{7} \mathrm{OH}\right)_{2} \mathrm{H}^{+}\right\} \underset{\mathrm{k}_{3}}{\stackrel{\Delta}{\longrightarrow}}\left\{\left(\mathrm{C}_{3} \mathrm{H}_{6} \mathrm{O}\right) \mathrm{H}^{+}\right\}+\left(\mathrm{C}_{3} \mathrm{H}_{7}\right)^{+}+\left(\mathrm{H}_{3} \mathrm{O}\right)^{+}$

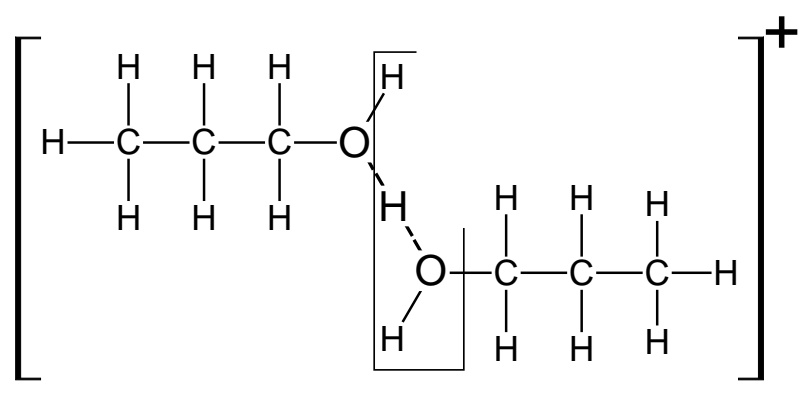


The $\mathrm{m} / \mathrm{z} 39$ fragment $\left(\mathrm{C}_{3} \mathrm{H}_{3}{ }^{+}\right)$was observed with PTRMS studies at electric fields of $138 \mathrm{Td}$ [27], and is thought to result from the sequential loss of $\mathrm{H}_{2}$ (8) and at this stage the tentative assignment for $\mathrm{C}_{3} \mathrm{H}_{3}+$ is a cyclic entity [34, 35].

$\left(\mathrm{C}_{3} \mathrm{H}_{7}\right)^{+} \longrightarrow\left(\mathrm{C}_{3} \mathrm{H}_{5}\right)^{+} \longrightarrow\left(\mathrm{C}_{3} \mathrm{H}_{3}\right)^{+}$

The absence of a distinctive protonated monomer signal may be explained if the dissociation of the proton bound dimer was rate limiting, and followed by subsequent fast dissociation/fragmentation $\left(\mathrm{k}_{1}<\mathrm{k}_{2}\right)$. This has been observed with butyl acetates in a conventional IMS drift tube [36], and with esters in other DMS studies [32]. This behaviour has been attributed to the energy partition and the heat capacity of the larger proton bound dimer compared to the protonated monomer. The onset of ion decomposition is remarkably sensitive to ion mass and in the instance of ethanol, the difference in mass between protonated monomer and proton bound dimer is only $46 \mathrm{Da}$. Nonetheless, the protonated ethanol monomer at $70^{\circ} \mathrm{C}$ was decomposed completely at $E_{D}=78 \mathrm{Td}\left(19.5 \mathrm{kV} . \mathrm{cm}^{-1}\right)$ while the proton bound dimer persists until $E_{D}=103 \mathrm{Td}\left(25.75 \mathrm{kV} . \mathrm{cm}^{-1}\right)$.

The dispersion plots acquired at $115{ }^{\circ} \mathrm{C}$ and $130^{\circ} \mathrm{C}$ (Figure 5), show two further dissociation/decomposition processes, albeit at lower yields. The feature observed at $E_{D}=$ $110 \mathrm{Td}\left(27.5 \mathrm{kV} \cdot \mathrm{cm}^{-1}\right)$ at $130^{\circ} \mathrm{C}$ is consistent with the formation of $\mathrm{C}_{3} \mathrm{H}_{3}{ }^{+}$(8). The feature branching from the hydrated proton reaction ion peak at $E_{D}=72 \mathrm{Td}\left(18 \mathrm{kV} \cdot \mathrm{cm}^{-1}\right)$ and $E_{C}=$ $0.75 \mathrm{Td}\left(-118 \mathrm{~V} . \mathrm{cm}^{-1}\right)$ is perhaps consistent with the formation $\left(\mathrm{C}_{3} \mathrm{H}_{7}\right)^{+}$from the decomposition of a proton bound dimer (7). In PTR-MS studies at intermediate (115 Td) to high field strengths (138 Td) the fragment ion observed for propan-1-ol was $\mathrm{C}_{3} \mathrm{H}_{5}{ }^{+}$[27]; the possible generation of such a fragment cannot be excluded in this study.

\section{Butan-1-ol}

In Figure 6 the dispersion plots for butan-1-ol obtained at $40^{\circ} \mathrm{C}, 45^{\circ} \mathrm{C}, 50^{\circ} \mathrm{C}$ and $70^{\circ} \mathrm{C}$ show the fragmentation of protonated monomer with little or no proton bound dimer present. The formation of a dissociation/fragmentation product ion at $40^{\circ} \mathrm{C}$ and $E_{D}=90 \mathrm{Td}\left(22.5 \mathrm{kV} . \mathrm{cm}^{-}\right.$ $\left.{ }^{1}\right)$ is clearly evident with $E_{D}$ decreasing to $E_{D}=59 \mathrm{Td}\left(17.5 \mathrm{kV} . \mathrm{cm}^{-1}\right)$ as the cell-temperature 
increases to $70^{\circ} \mathrm{C}$. This observation is consistent with the formation of the $\mathrm{m} / \mathrm{z}=57$ dissociation/fragmentation ion observed in the mass spec study.

\section{Dehydration of protonated monomers with the formation of hydrated protons}

Reaction (7) postulates that $\left(\mathrm{H}^{+}\left(\mathrm{H}_{2} \mathrm{O}\right)_{n}\right)$ may be generated during dissociation and this was noted above and in Figure 6; and was evident in the 3D plots of Figures 5 and 7. This phenomenon was observed for propan-1-ol and butan-1-ol. Of further interest was the butan-1-ol response indicated the possibility that two distinct dehydration reactions were occurring with two phases of $\left(\mathrm{H}^{+}\left(\mathrm{H}_{2} \mathrm{O}\right)_{n}\right)$ generation.

\section{Clustering in DMS drift tube.}

The apparent shift of the $E_{C}$ maximum for the protonated monomer towards that for the proton bound dimer occurred over a relatively narrow range of experimental conditions of temperatures and vapour concentrations. This observation was unmistakable and repeatable and is apparent in Figures 1 and 2. The number of ion-neutral collisions during the low-field segment of the waveform was well below 1, and the observed behaviour consequently cannot be described as a cluster-decluster mechanism with modification of the alpha-function. Modification of the alpha function was observed at higher vapour levels as seen in Figures 1 and 2, where a cool ion can be solvated through 2 or more collisions $[37,38,39,40]$. It is helpful to emphasise the convergence of the protonated monomer $E_{C}$ maximum to the proton bound dimer compensation field maximum must be due to ion molecule collisions over time periods greater than 600 ns (the duration of the low field segment of the dispersion waveform) and is consistent with residence time of ions in the drift tube (1 to $2 \mathrm{~ms}$ ). Two possible interpretations may be considered.

The ion may be envisaged as entering the drift tube as a protonated monomer (Dotted line in Figure S4). A residence time of $2 \mathrm{~ms}$ in the DMS ion filter gives enough time for the ion to collide with a neutral alcohol molecule $(\mathrm{ROH})$, creating a proton bound dimer with a different trajectory (Dashed line in Figure S4). The result will be a shift in the ion's position on the $E_{C}$ scale such that it falls between the monomer and proton bound dimer positions. This phenomenon is concentration dependent, the higher the concentration, the earlier the collision takes place, and the closer the modified trajectory will be to that of a proton bound 
dimer generated in the reaction region. The two distinct signals are seen to converge with the protonated monomer signal appearing to shift and merge with the proton bound dimer signal as the concentration increases. The ion entered the drift tube as a protonated monomer and was converted to proton bound dimer emerging at a CV which was a measure of where the conversion occurred in the ion-filter.

The alternative explanation invokes exchange between the protonated monomer and proton bound dimer during transit through the ion-filter. Collision numbers at this concentration and residence time are 20 to 50. While such interactions may be expected to cause band broadening it has been shown that exchange of neutral adducts on an ion core can be located over a range of drift times without band broadening or resolution of the two ion clusters providing the exchange is rapid in comparison to residence time in the drift tube [41].

Increasing the cell-temperature inhibited this phenomenon which was eliminated at celltemperatures above $130^{\circ} \mathrm{C}$. While the two mechanisms cannot be unpacked from the experiments here, these observations add an additional layer of complexity onto the fragmentation behaviour.

\section{CONCLUSIONS}

The experiments in this study isolated dissociation/fragmentation product ions that have not been previously described. The ion chemistries appear to be similar to those reported in PTRMS studies [27]. The formation of the fragment ion at m/z 39 from propan-1-ol and butan-1-ol raises the possibility of multistep reactions and the possibility of further ionneutral reactions. Follow-on experiments with deuterated standards at higher mass accuracy will be a logical continuation from this preliminary study to better establish the reactions and mechanisms observed here.

Whenever a DMS measurement with alcohols is above $80^{\circ} \mathrm{C}$, dehydration reactions are possible and will be controlled by $T_{(e f f)}$ which is determined by the combination of the experimental parameters of cell-temperature and $E_{D}$. The onset of changes in the spectral patterns at characteristic $\mathrm{T}$ and $\mathrm{E} / \mathrm{N}$ values varies with $\mathrm{C}$-number for all alcohols except methanol, which undergoes no fragmentation. The selection of these experimental parameters determines in large measure the resultant characteristics of the observed 
spectra, and the subsequent possible analytical utility of comparison of spectra between DMS platforms and laboratories.

Over a relatively narrow range of temperature and vapour concentration, ion peaks undergo a slide in $E_{C}$ maxima values, and this cannot be attributed to alpha function modification. Rather, the ion is being transformed during residence in the DMS analyser. Applications for measuring alcohols should account for these behaviours [42]. Future developments of DMS, should address these factors by designing the ionisation inlet to ensure ions pass into the DMS in filter in purified gases and unreacted sample or matrix neutrals are vented.

\section{ACKNOWLEDGEMENTS}

The authors wish to thank: the Engineering and Physical Science Research Council alongside John Hoggs Technical Solutions for the support of D.M. Ruszkiewicz through an Industrial Case Studentship Award; the researchers at NMSU for their help with the APCI MS studies, and Dr Matthew Turner at Loughborough University for his support of the laboratory experiments. 


\section{REFERENCES}

1 National Institute on Alcohol Abuse and Alcoholism URL: http://www.niaaa.nih.gov/alcohol-health/overview-alcohol-consumption/alcoholfacts-and-statistics, visited 23 August 2015

2 Office for National Statistics; Defining alcohol-related deaths; discussion released 18 July 2006, URL: http://www.ons.gov.uk/ons/index.html, visited 24 August $\underline{2015}$

3 Winek C.L, Wahba W.W, Wienek Jr W.W and Balzer T.W.; Forensic Science International (2001) 122; pp 107-123

4 Brahmi N, Blel Y, Abidi N, Kouraichi N, Thabet H, Hedhili A, and Amamou M. Methanol poisoning in Tunisia: report of 16 cases. Clin. Toxicol. (Phila). 2007;45(6) pp717-20

5 Williams GF, Hatch FJ, Bradley MCand case study of four patienl. Aust. Crit. Care (1997); 10; pp 113-18

6 The Wall Street Jurnal; After Poisonings, Czech Republic Bans Hard Liquor, URL:

http://www.wsj.com/articles/SB1000087239639044399560457800042138642884 $\underline{6 \text {, visited } 24 \text { August } 2015}$

7 EPA No CASR. ( AEGLs ) METHANOL report 2005 (67), URL: www.epa.gov visited 13 July 2015

8 The NHS Information Centre; Statistics on Alcohol; England, 2013, p.53 URL: www.hscic.gov.uk/catalogue/PUB10932/alc-eng-2013-rep.pdf, visited 23 August 2015

9 U.S Department of Health and Human Services NIAAA; Alcohol and the brain neuroscience and neurobehavioral; In: Tenth Special Report to the US Congress on Alcohol and Healt; Rockville, MD. National Institute on Alcohol Abuse and Alcoholism (2000) pp 67-157

Stewart S, Jones D, Day CP. Alcoholic liver disease: new insights into mechanisms and preventative strategies. Trends Mol. Med. (2001) 9; pp 408-413

11 Rydberg U. andSkerfving S.; The toxicity of ethanol. The tantative risk evaluation; Alcohol Intoxication and Withdrawal; Plenium Press, New York pp 403-419

12 Stremski E and Hennes H.; Pediatr Emerg Care (2000) 4; pp 238-40

13 BBC News; Prisoner drunk on swine flu gel; URL http://news.bbc.co.uk/1/hi/england/dorset/8272799.stm, visited 29 September $\underline{2015}$

14 CBSNews; Hand sanitizers linked to alcohol poisoning in kids, URL: http://www.cbsnews.com/news/hand-sanitizers-linked-to-alcohol-poisoning-inkids/, visited 29 September 2015

15 National library of medicine; Toxicology data network - isopropanol, URL:http://toxnet.nlm.nih.gov/, visited 13 July 2015 
Pereira P., Santos E., Ferreira T., Andrade J.; Talanta (1999) 49; pp 245-252

Giang Y, Wang S., Tsai C., Lee M. and Ng C.; Forensic Science Journal (2007) 6; pp 1-19

Macchia T., Mancinelli R., Gentili S, Lugaresi E., Raponi A., Taggi F.; Journal of Analytical Toxicology (1995) 19; pp 241-246

Gallego E., Roca X., Perales J., Guardino X.; Journal of Environmental Sciences (2008) 21; pp 333-339

Ghimenti S., Tabucchi S., Bellagambi F., Lomonaco T, Onor M., Trivella M., Fuoco R., Di Francesco F.; Journal of Pharmaceutical and Biomedical Analysis (2015) 106; pp 218-223

Jones A., Mardh G., Anggard E., Pharmacology Biochemistry and Behaviour (1983) 18; pp 267-272

Sielemann S, Baumbach J., Schmidt H., Pilzecker P.; Analytica Chimica Acta (2001) 431; pp 293-301

Bocos-Bintintan V., Moll V., Flanagan R., Thomas P.; International Journal for Ion Mobility Spectrometry (2010) 13; 55-63

Limero T., Reese E., Wallace W., Cheng P. and Trowbridge J.; International Journal for Ion Mobility Spectrometry (2012) 15; pp 189-198

Eiceman G. and Karpas Z.; Ion Mobility Spectrometry; 2005, Taylor and Francis Group

Inomata S., Tanimoto H.; Int. J. Mass Spec. (2009) 285; pp 95-99

Brown P., Watts P., Märk T., Mayhew C.; Int. J. Mass Spec. (2010) 294; pp 103111

Purves R. W., Ozog, A. R., Ambrose, S. J., Prasad, S., Belford, M., and Dunyach J. J., J. Am. Soc. Mass Spectrom. (2014) 25 pp 1274-1284

Dillon L., Stone V., Croasdell L., Fielden P., Goddard N. and Thomas P. The Analyst (2010) 135; pp 306-14

Khayamian T., Tabrizchi M., Taj N.; Anal. Chem. (2001) 370, pp 1114-1116

30 Nelson G.,Gas Mixtures: Preparation and Control, Lewis Publishers Inc., 1992

An X., Eiceman G., Rodriguez J. Stone J. A., Int. J. Mass Spec. (2011) 303; pp 181-190

An X., Eiceman G., Räsänen R., Rodriguez J., Stone J., J. Phys. Chem. A (2013) 117; pp 6389-6401

Gui-xia Liu, Ze-sheng Li,* Yi-hong Ding, Qiang Fu, Xu-ri Huang, Chia-chung Sun, and Au-chin Tan, J. Phys. Chem. A (2002) 106, pp 10415-10422

Mabrouki R., Ibrahim Y., Enli Xie, Meot-Ner (Mautner) M., and El-Shall M.S., J. Phys Chem. A (2006) 110, pp 7334-7344

Eiceman G. A., Shoff D. B, Harden C. S., and Snyder A.P., Int. J. Mass Spec. Ion Proc. (1988) 85, pp 265-275. 
37 Eiceman G., Krylova N., Krylov E., J. Stone; Int J Ion Mobil Spectrom (2003) 107; pp 3648-3652

38 Eiceman G., Krylov E., Krylova N., Nazarov E., Miller R.; Analytical Chemistry (2004) 76; pp 4937-4944

39 Rorrer L., Yost R.; International Journal of Mass Spectrometry (2011) 300; pp 173-181

40 Schneider B., Covey T., Nazarov E.; International Journal for Ion Mobility Spectrometry (2013) 16; pp 207-216

41 Preston J., Rajadhyax L.; Anal. Chemistry (1988) 34; pp 31-34

42 Criado-García L., Ruszkiewicz D. M., Eiceman G. A., and Thomas C. L. P.; J. Breath Res. (2016) 10; 017101 


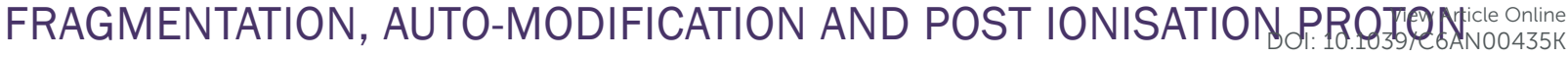
BOUND DIMER ION FORMATION: THE DIFFERENTIAL MOBILITY SPECTROMETRY OF LOW MOLECULAR WEIGHT ALCOHOLS

D.M. Ruszkiewicz, C.L.P. Thomas*, G.A. Eiceman

Wednesday, 18 May 2016

\section{FIGURES}

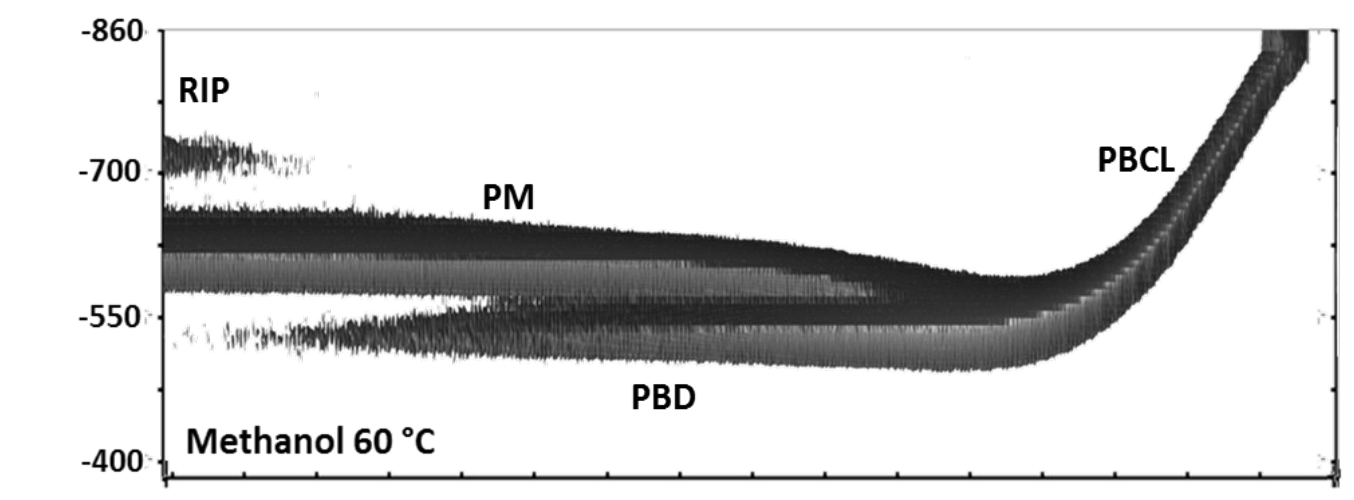

$-3.4$
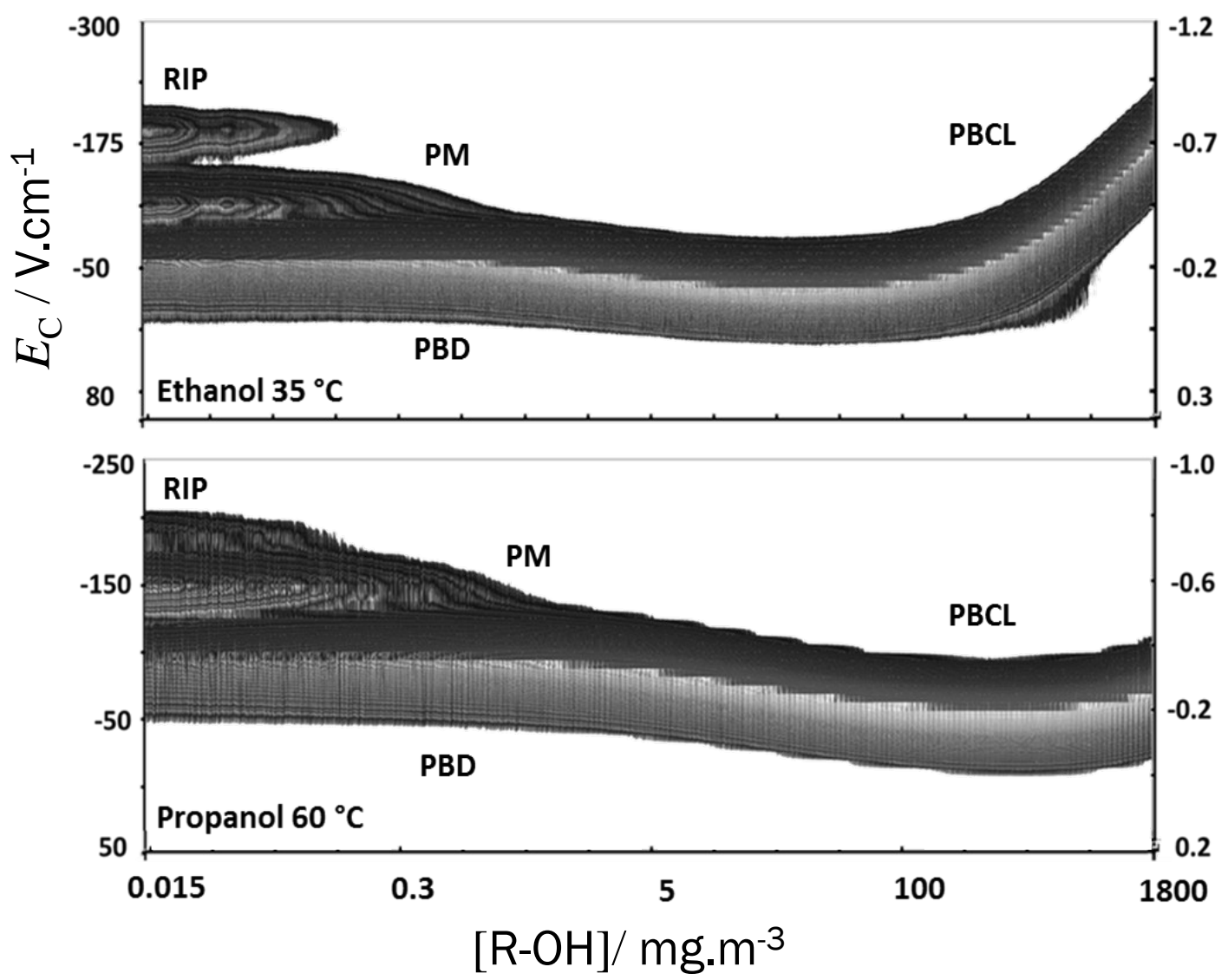

Figure 1 Topographic plots of DMS signal intensity, compensation-field $E_{C}$ and gas-phase concentration $[\mathrm{R}-\mathrm{OH}]$ from an exponential dilution flask for the first three n-alcohols (methanol-top, ethanol-middle and propanol-bottom) Data were collected over the concentration range from $15.0 \mu \mathrm{g} \cdot \mathrm{m}^{-3}(\mathrm{~g}) 1.80 \mathrm{~g} \cdot \mathrm{m}^{-3}(\mathrm{~g})$ at dispersion fields of $117.6 \mathrm{Td}$ for methanol, and $72 \mathrm{Td}$ for ethanol and $88 \mathrm{Td}$ for propanol. $\left(29.4 \mathrm{kV} . \mathrm{cm}^{-1} 18 \mathrm{kV} . \mathrm{cm}^{-1}\right.$, and $22 \mathrm{kV} . \mathrm{cm}^{-1}$ respectively) and DMS ion-filter temperatures of $60^{\circ} \mathrm{C}, 35^{\circ} \mathrm{C}$ and $60^{\circ} \mathrm{C}$ respectively for methanol, ethanol and propanol. 


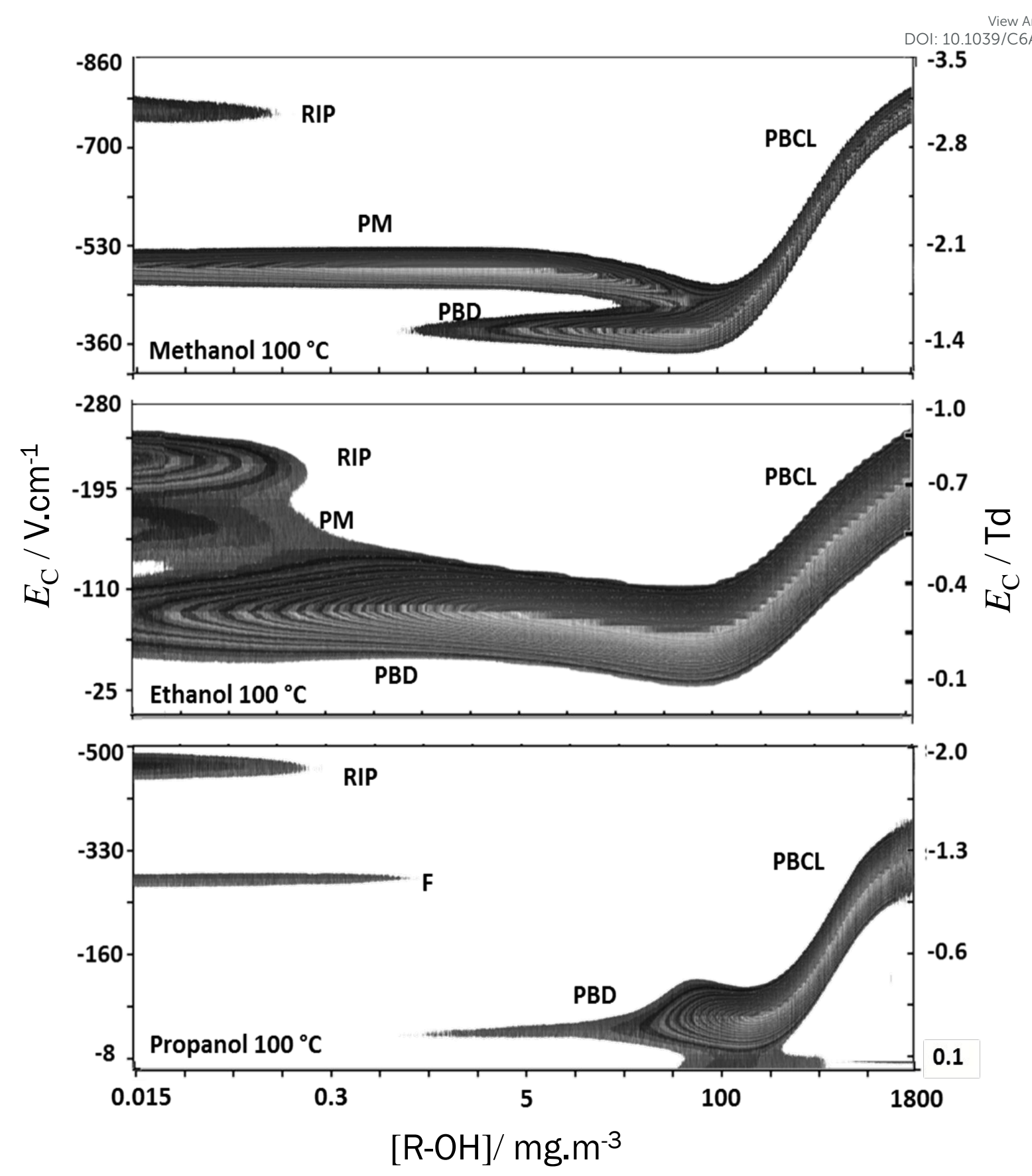

Figure 2. Topographic plots of intensity, compensation field and vapour concentration from measurements by a DMS analyser equipped with exponential dilution flask for first three $n$-alcohols (methanol-top, ethanol-middle and propanol-bottom). Data were collected over the concentration range from $\left.1.80 \mathrm{~g} \cdot \mathrm{m}^{-3} \mathrm{~g}\right)$ to $15.0 \mu \mathrm{g} \cdot \mathrm{m}^{-3}(\mathrm{~g})$ at dispersion fields of $117.6 \mathrm{Td}$ for methanol, and $72 \mathrm{Td}$ for ethanol and $88 \mathrm{Td}$ propanol (29.4 kV.cm-1 $18 \mathrm{kV} . \mathrm{cm}^{-1}$ and $22 \mathrm{kV} . \mathrm{cm}^{-1}$ respectively), with the DMS ion-filter temperature maintained at $100^{\circ} \mathrm{C}$. 

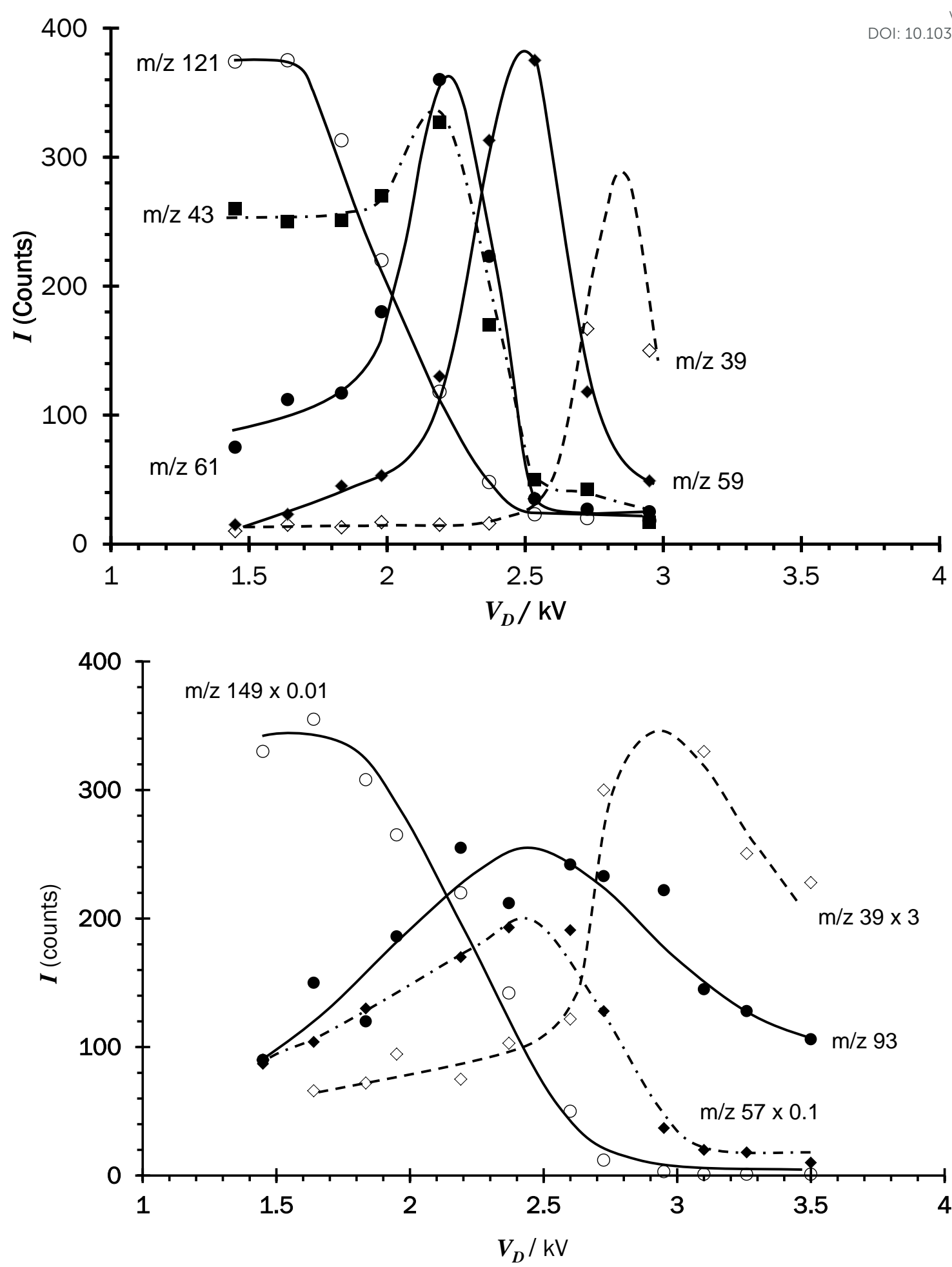

Figure 3. Ion intensity $I$ vs. applied ion heating voltage $V_{D}$, showing the effect of dispersion field amplitude $\left(V_{D}\right)$ on ion dissociation at a DMS temperature of ca. $80^{\circ} \mathrm{C}$. Top: Ions associated with propanol showing the dissociation of a proton bound dimer $(\mathrm{m} / \mathrm{z}=$ $121)$ to yield a protonated monomer $(\mathrm{m} / \mathrm{z}=61)$ and a dehydration fragment ion $(\mathrm{m} / \mathrm{z}$ $=43$ ). Increasing $V_{D}$ resulted in further ion dissociation with the products at $\mathrm{m} / \mathrm{z}=59$ and finally $\mathrm{m} / \mathrm{z}=39$. Bottom: ions associated with butanol (scaled to enable straightforward comparison). Here the proton bound dimer dissociates to a dehydration dissociation product ion $(\mathrm{m} / \mathrm{z}=57$ at ca. $10 \%$ yield) and a hydrated protonated monomer ( $\mathrm{m} / \mathrm{z}=93$ at ca. $1 \%$ yield). Above $V_{D}=2.5 \mathrm{kV}$ the $\mathrm{m} / \mathrm{z}=39$ dissociation product was observed once more [27]. 

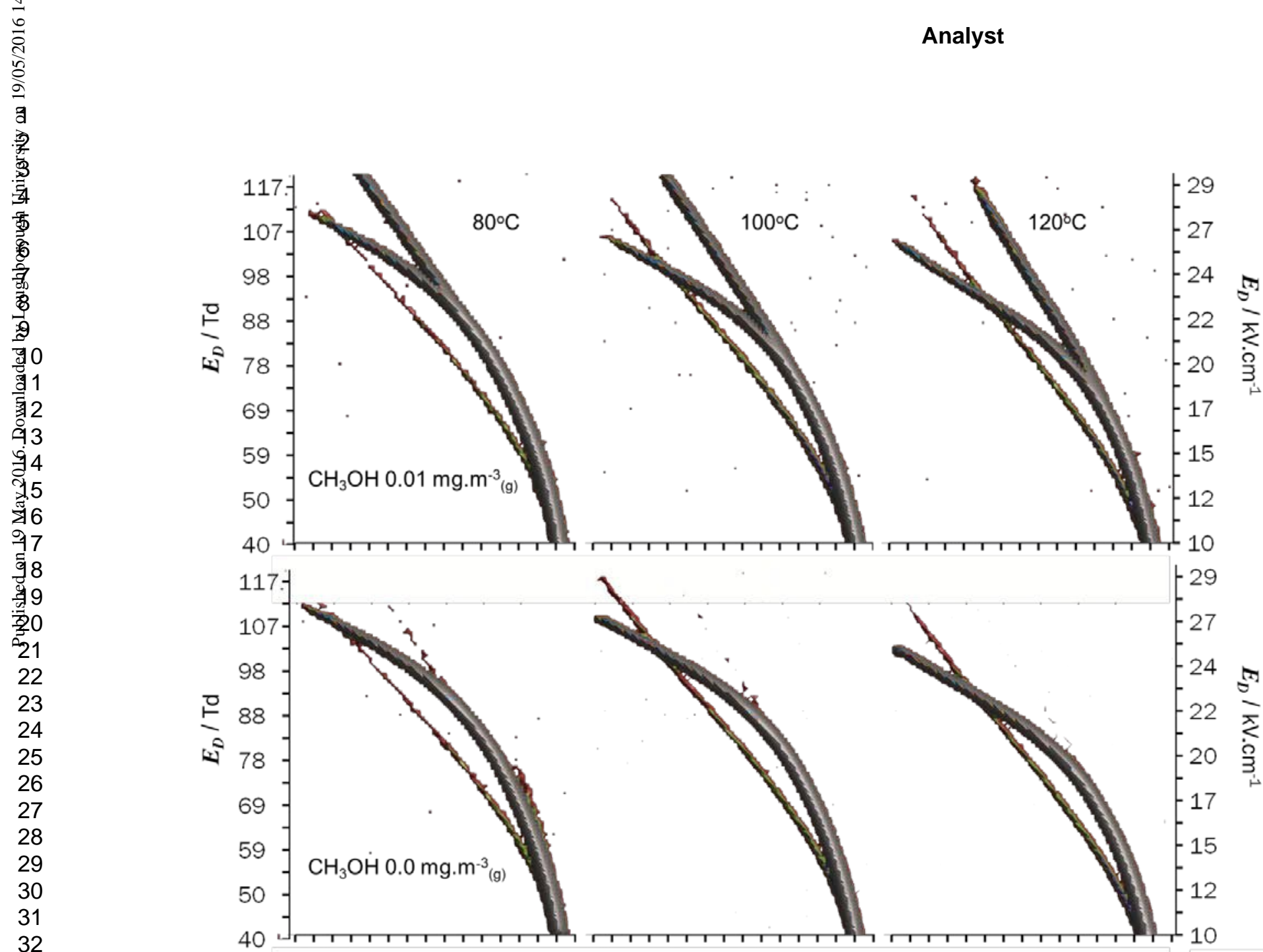

일

\section{$E_{C} / \mathrm{V} . \mathrm{cm}^{-1}$}

Figure 4. Dispersion plot intensity contour maps showing the combined effect of cell-temperature and dispersion field $\left(E_{D}\right)$ on compensation field $\left(E_{C}\right)$. Top: dispersion plots of methanol at $\approx 0.01 \mathrm{mg} \cdot \mathrm{m}^{-3}(\mathrm{~g})$. Bottom: blank dispersion plots. While the effect of temperature on the reactant ion hydrate proton clusters is evident, the methanol protonated monomer does not form dissociation ions and its dispersion behaviour is not affected significantly by increases in temperature over the range $80^{\circ} \mathrm{C}$ to $120^{\circ} \mathrm{C}$. 

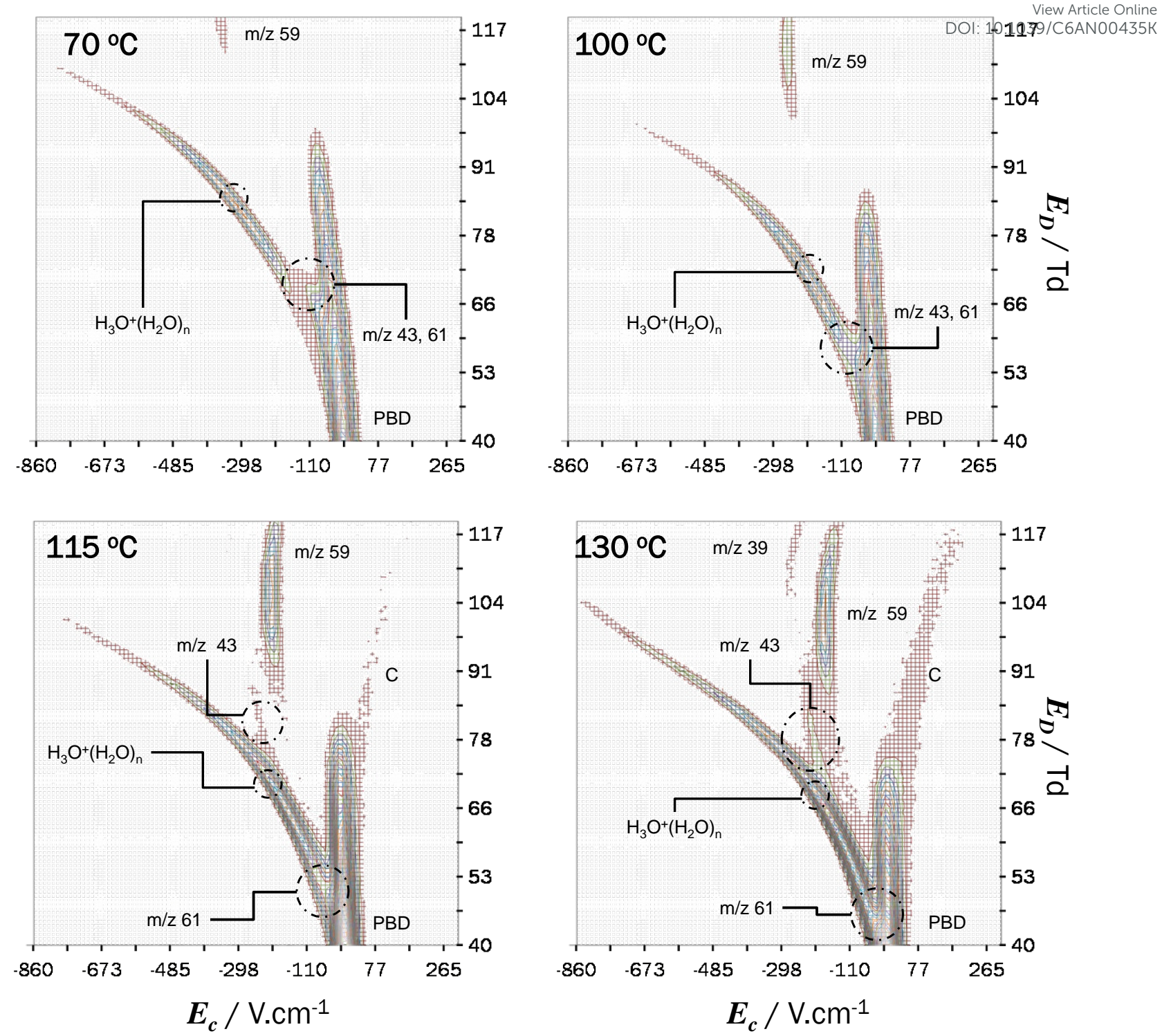

Figure 5. Dispersion plot intensity contour maps showing the combined effect of celltemperature and dispersion field $\left(E_{D}\right)$ on compensation field $\left(E_{C}\right)$ for n-propanol at $\left.0.02 \mathrm{mg}^{-3} \mathrm{~m}^{-3} \mathrm{~g}\right)$. The mass assignments are tentative and inferred from the DMS-MS data.

Key: $\quad$ PBD: proton bound dimer, perhaps accompanied by mixed cluster ions; and, C: trace contamination attributed to siloxanes. 

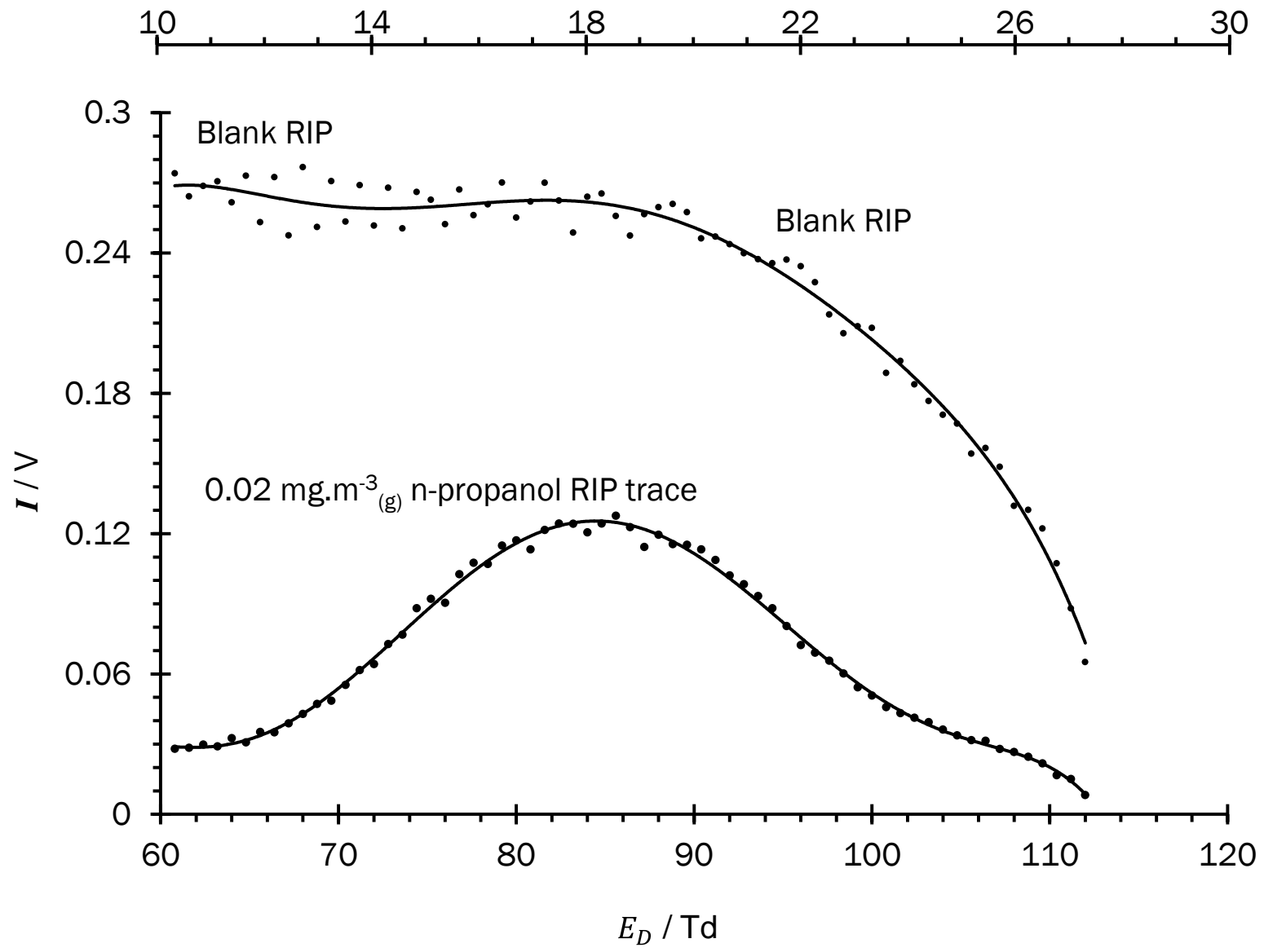

Figure 6. Evidence of $\left(\mathrm{H}^{+}\left(\mathrm{H}_{2} \mathrm{O}\right)_{n}\right)$ formation with increasing $E_{D}$. The top trace shows the effect of increasing $E_{D}$ on intensity of the $\left(\mathrm{H}^{+}\left(\mathrm{H}_{2} \mathrm{O}\right)_{n}\right)$ signal at an ion-filter temperature of $70^{\circ} \mathrm{C}$. The signal intensity decays with the reducing acceptance aperture of the DMS. The bottom trace shows the $\left(\mathrm{H}^{+}\left(\mathrm{H}_{2} \mathrm{O}\right)_{n}\right)$ signal intensity observed under the same dispersion fields in the presence of $0.02 \mathrm{mg}^{-3} \mathrm{~m}(\mathrm{~g})$ propanol. At the start of the dispersion field programme the $\left(\mathrm{H}^{+}\left(\mathrm{H}_{2} \mathrm{O}\right)_{n}\right)$ signal reflects the depletion of the reactant ion peak to form PBD and PM. Increasing $E_{D}$ resulted in a signal profile indicative of the regeneration of $\left(\mathrm{H}^{+}\left(\mathrm{H}_{2} \mathrm{O}\right)_{n}\right)$ in line with the dissociation and fragmentation processes postulated in Eq. 9, 10 and 11. 

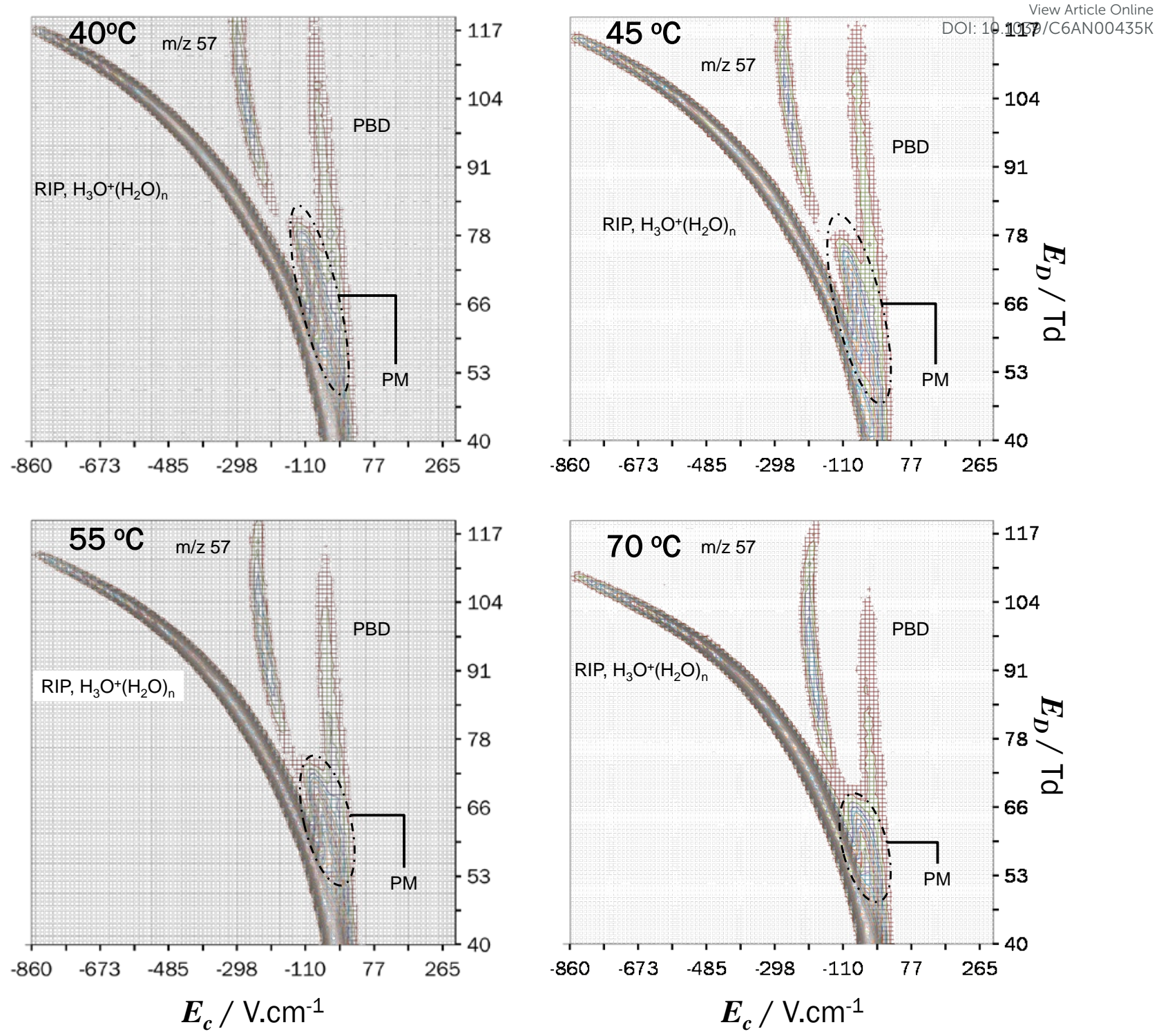

Figure 7 Dispersion plot intensity contour maps showing the combined effect of celltemperature and dispersion field $\left(E_{D}\right)$ on compensation field $\left(E_{C}\right)$ for $\mathrm{n}$-butanol at 0.01 mg. $m^{-3}(g)$.

Key: $\quad$ PBM: proton bound monomer; PBD: proton bound dimer. 